\title{
Antimetastatic effects of cordycepin mediated by the inhibition of mitochondrial activity and estrogen-related receptor $a$ in human ovarian carcinoma cells
}

\author{
Chia-Woei Wang ${ }^{1,2}$, Wei-Hsuan Hsu ${ }^{3}$, Chen-Jei Tai ${ }^{1,2,4,5}$ \\ ${ }^{1}$ Graduate Institute of Clinical Medicine, College of Medicine, Taipei Medical University, Taipei 11042, Taiwan \\ ${ }^{2}$ Department of Obstetrics and Gynecology, School of Medicine, College of Medicine, Taipei Medical University, Taipei 11042, Taiwan \\ ${ }^{3}$ Biochemical Process Technology Department, Center of Excellence for Drug Development, Biomedical Technology and \\ Device Research Laboratories, Industrial Technology Research Institute, Hsinchu 30068, Taiwan \\ ${ }^{4}$ Department of Traditional Chinese Medicine, Department of Internal Medicine, Taipei Medical University Hospital, Taipei \\ 11042, Taiwan \\ ${ }^{5}$ Traditional Herbal Medicine Research Center, Taipei Medical University Hospital, Taipei 11042, Taiwan
}

Correspondence to: Chen-Jei Tai, email: chenjtai@tmu.edu.tw

Keywords: cordycepin, mitochondrial fusion, mitochondrial fission, estrogen-related receptor (ERR)- $a$, antimigration

Received: September 16, 2016

Accepted: November 23, 2016

Published: December 09, 2016

\section{ABSTRACT}

Cordycepin ( $3^{\prime}$-deoxyadenosine) is a compound for antitumor, which has been found to exert antiangiogenic, antimetastatic, and antiproliferative effects, as well as inducing apoptosis. However, the association between cancer metastasis and mitochondrial activity in cordycepin-treated ovarian carcinoma cells remains unclear. The 50 and $100 \mu \mathrm{M}$ of cordycepin inhibits mitochondrial fusion and induces mitochondrial fission, respectively. These suggested that cordycepin showed the down-regulation of mitochondrial function and limitation of energy production. Because of activation of mitochondria and generation of energy are needed in cancer cell migration/invasion. After $\mathbf{2 4} \mathrm{h}$ treatment, cordycepin suppresses epithelial-mesenchymal transition and migration in ovarian carcinoma cells through inhibiting estrogen-related receptor (ERR)-a. The ERRa is a co-transcription factor for gene expressions associated with mitochondrial fusion. Our results indicate that cordycepin suppresses metastasis and migration of ovarian carcinoma cells via inhibiting mitochondrial activity in non-toxic concentrations, and cordycepin has potential benefits in ovarian cancer therapy.

\section{INTRODUCTION}

Ovarian cancer is a common gynecological cancer and is always found in woman worldwide. A high mortality rate is found in ovarian cancer patients when tumor invasion and metastasis. Clinically, onsurgical therapies such as chemotherapy or radiotherapy is always used to treat patients with ovarian cancer [1]. Ovarian cancer could be categorized into three subtypes, including (I) epithelial carcinomas, (II) stromal carcinomas, and (III) germ cell tumors [2], and the epithelial ovarian carcinomas is most found in patients in ovarian cancer cases [3,4]. In addition, this ovarian epithelial tumor cells would result in migration/ invasion through epithelial-mesenchymal transition (EMT) thereby entering into blood steam [5-8]. Several epithelial markers such as (I) epithelial keratins included E-cadherin, occludins, claudins, and desmoplakin are down-regulated and (II) acquire mesenchymal traits included vimentin, $\mathrm{N}$-cadherin, fibronectin, and $\alpha$-smooth muscle actin are upregluated while development of EMT in cancer cells, these results will increase metastatic ability [9].

Cordycepin (3'-deoxyadenosine) is an antitumor compound isolated from Cordyceps. Recently, many studies have been reported that cordycepin shows antiangiogenic, antimetastatic, antiproliferative effects and apoptosis induction [10-14]. The association between migration and invasion and mitochondrial activity in cordycepin-treated ovarian carcinoma cells remains unclear, hence, cordycepin was tested for suppressing the migration and invasion of ovarian carcinoma cells and determined the inhibitory effects of cordycepin on the mitochondrial activity and EMT. Moreover, we 
have demonstrated that EMT and mitochondrial fusion induction were involved in metastasis in this study.

\section{RESULTS}

\section{Cell viability and mitochondrial activity in cordycepin-treated OVCAR-3 cells}

Ovarian carcinoma cells (ES-2, SKOV-3, and OVCAR-3) were treated with cordycepin for $24 \mathrm{~h}$; subsequently, cell viability was assessed through crystal violet staining method, which was not affected by mitochondrial interference [16]. Cell viability of ES-2, SKOV-3, and OVCAR-3 cells were significantly decreased after treating with 150 or $200 \mu \mathrm{M}$ cordycepin for $24 \mathrm{~h}$ while $10-100 \mu \mathrm{M}$ cordycepin did not cause the cell death (Figure 1A).

3-(4,5-Dimethylthiazol-2-yl)-2,5-diphenyltetrazolium bromide (MTT) reduction is one of the most frequently used methods for measuring cell proliferation through the evaluation of mitochondrial activity. MTT reaction was used to investigate mitochondrial activity in ES-2, SKOV3 , and OVCAR-3 cells. Notably, 50-200 $\mu \mathrm{M}$ cordycepin markedly reduced the MTT reaction. In contrast to crystal violet staining, we considered cell death as the major reason for low MTT reaction at 150 or $200 \mu \mathrm{M}$ of cordycepin treatment for $24 \mathrm{~h}$. Hence, 50, 75, and $100 \mu \mathrm{M}$ cordycepin should be noncytotoxic for attenuating mitochondrial activity (Figure 1B).

In the MTT assay, both mitochondrial morphology and membrane potential are indices for mitochondrial function. Fission and fusion are need to have balance for regulations of cell growth, mitochondrial redistribution, and energy production. These circumstances plays important roles in apoptosis and mitophagy [16]. Data showed that treating with 50 and $100 \mu \mathrm{M}$ cordycepin changed the mitochondrial distribution and induced mitochondrial fission, respectively (Figure 2A). Mitochondrial membrane potential is a crucial parameter of mitochondrial function that is used as an indicator of cell health. JC-1 is a lipophilic, cationic dye that can selectively enter mitochondria and reversibly change its color from green to red with increasing
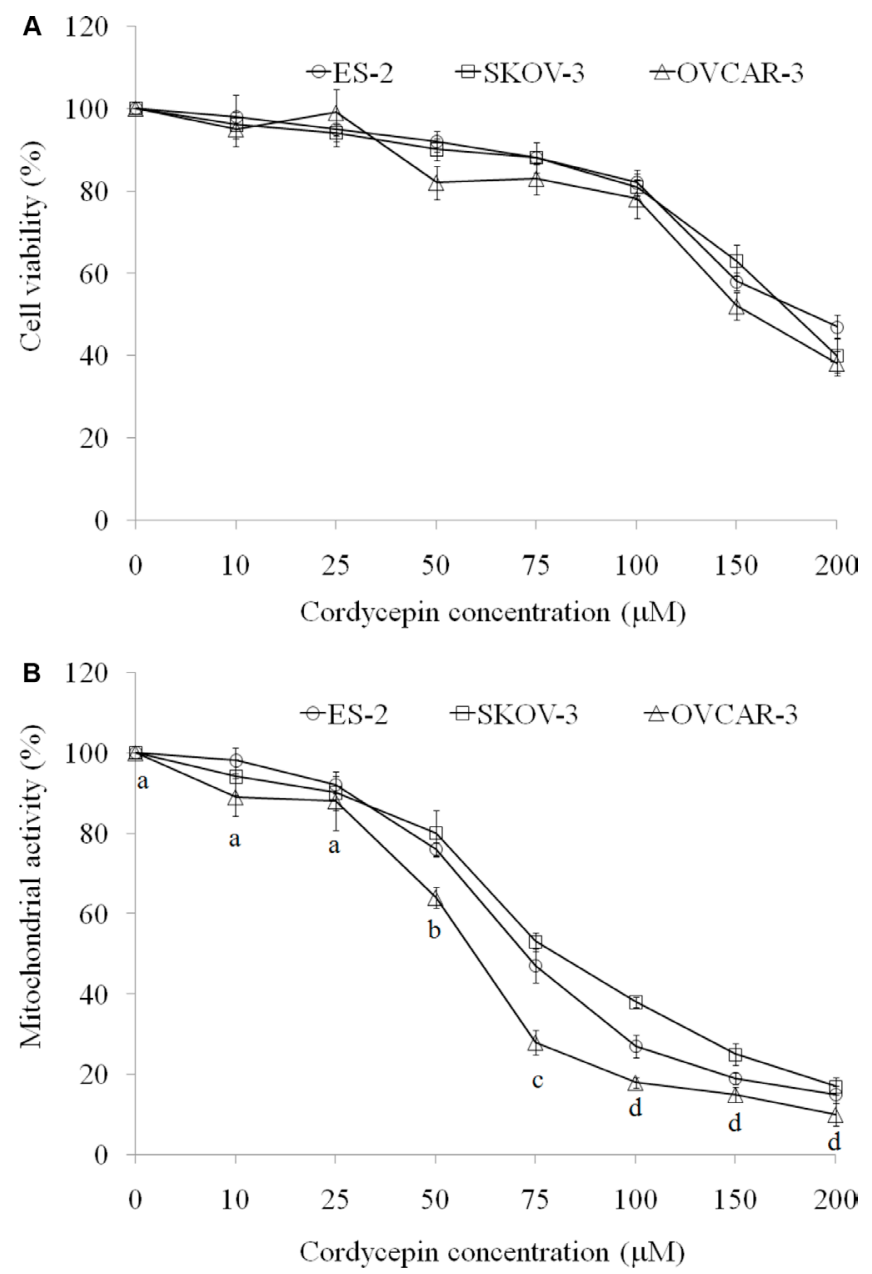

Figure 1: The effects of various concentration of cordycepin on (A) cell viability (crystal violet stain) and (B) mitochondrial activity (MTT assay) in the ES-2, SKOV-3, and OVCAR-3 human ovarian carcinoma cells after treatment for $\mathbf{2 4} \mathbf{h}$. Data were shown as mean $\pm \mathrm{SD}(n=3)$. The statistical significance was evaluated and showed in OVCAR-3 cells treated with cordycepin. 
membrane potential. In healthy cells with high levels of mitochondria, JC-1 spontaneously forms complexes known as J-aggregates, with intense red fluorescence. By contrast, in apoptotic or unhealthy cells with low mitochondrial membrane potential, JC-1 remains in the monomeric form, which shows only green fluorescence. Figure $2 \mathrm{~B}$ indicated that 50 and $100 \mu \mathrm{M}$ cordycepin treatment markedly decreased the mitochondrial membrane potential.

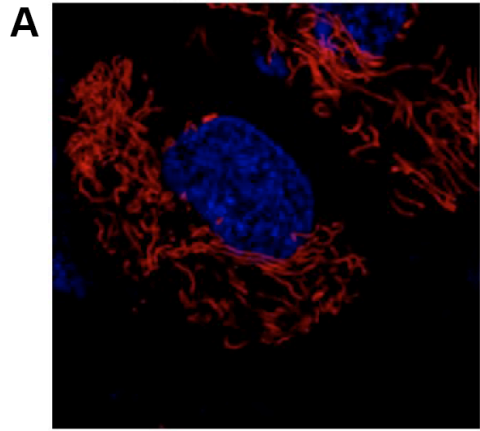

Blank

B

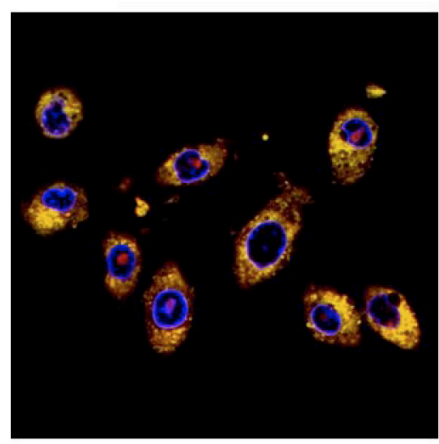

Blank

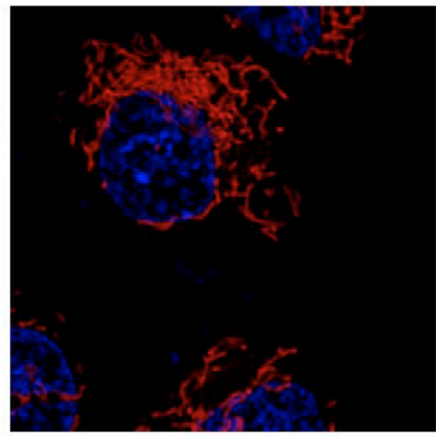

Cordycepin

$(50 \mu \mathrm{M})$

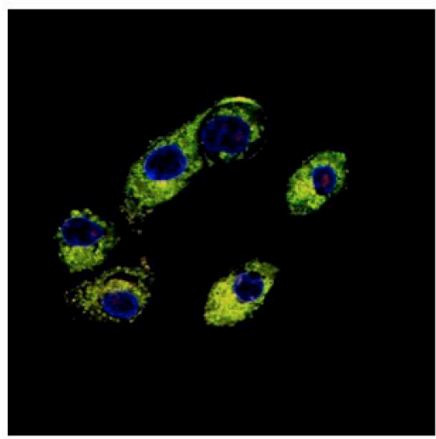

Cordycepin

$(50 \mu \mathrm{M})$

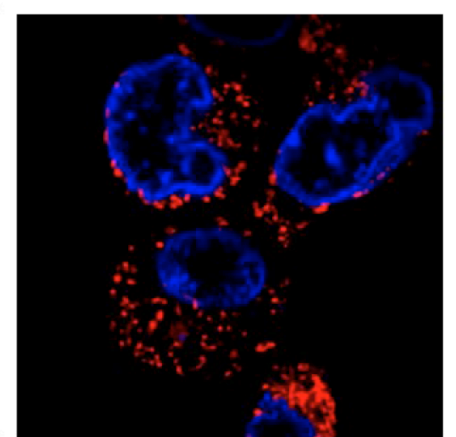

Cordycepin

$(100 \mu \mathrm{M})$

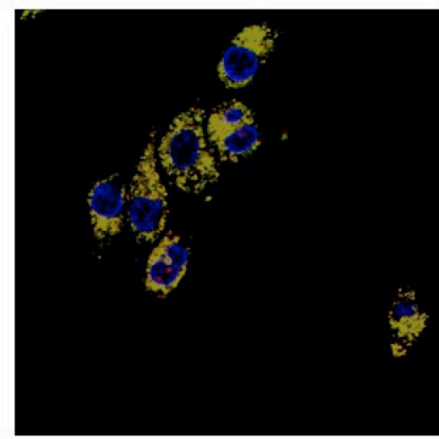

Cordycepin

$(100 \mu \mathrm{M})$

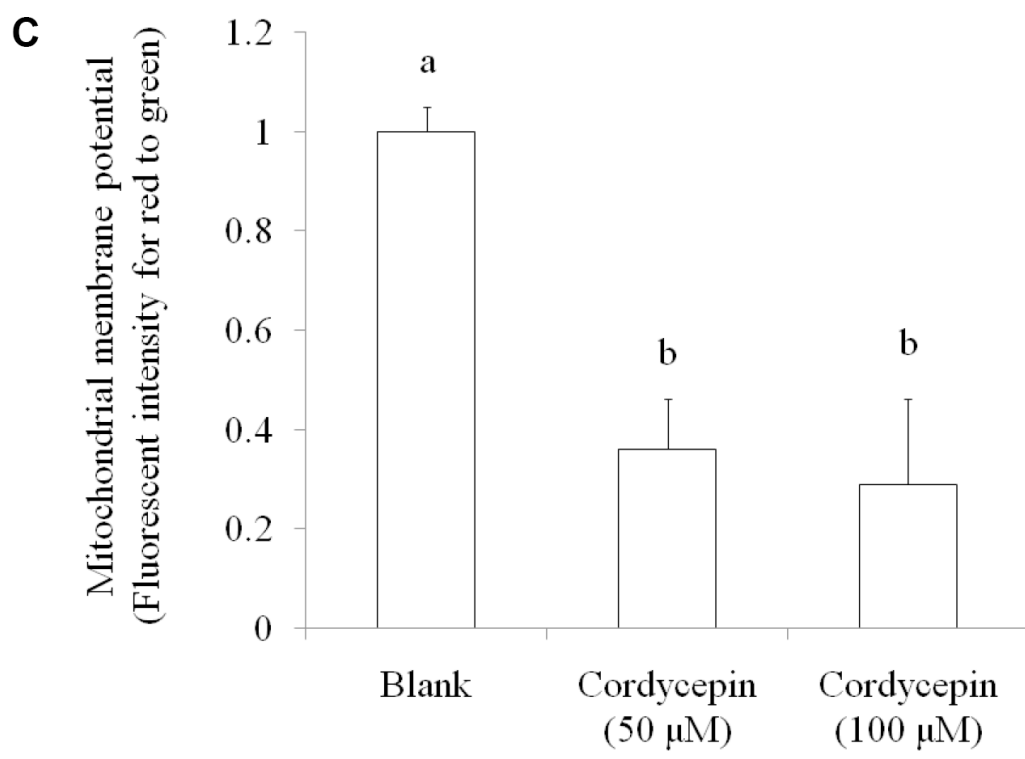

Figure 2: The effect of cordycepin (non-toxic dosage) on (A) mitochondrial morphology stained by MitoTracker Deep RedFM and (B) mitochondrial membrane potential stained by JC-1 in the OVCAR-3 ovarian carcinoma cells after $24 \mathrm{~h}$ treatment. (C) The statistical significance was evaluated and showed in mitochondrial membrane potential. Data were shown as mean $\pm \operatorname{SD}(n=3)$. 


\section{Effects of cordycepin on EMT and mitochondria fusion of OVCAR-3 cells}

EMT is a major mechanism involved in cancer metastasis [17], it also triggers cell proliferation and drug resistance $[18,19]$. Therefore, inhibition of EMT mediated by a novel medicine is a complementary therapeutic method for suppressions of metastasis and chemotherapy resistance [19]. 50 and $100 \mu \mathrm{M}$ cordycepin treatment for $24 \mathrm{~h}$ markedly increased E-cadherin level and decreased vimentin level in OVCAR-3 cells (Figure 3).

Mitochondrial fusion or fission state is accorded to mitochondrial division. Mitofusin (Mfn)-1 and -2 (Mfn$1 / 2$ ), and GTPase optic atrophy-1 are found to link two

A

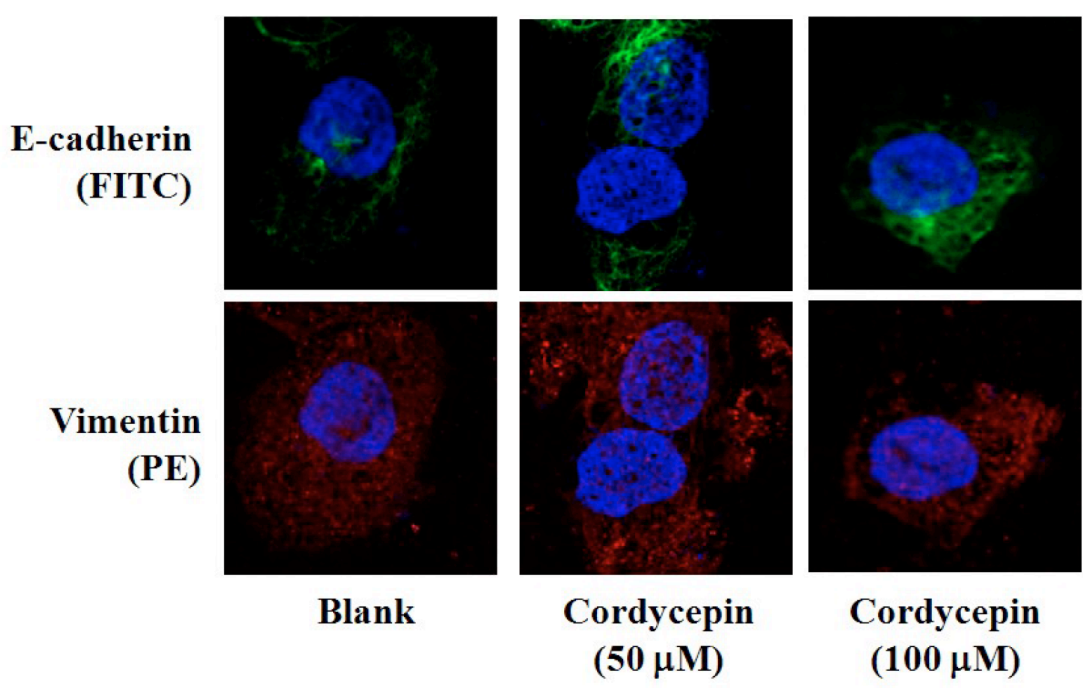

B

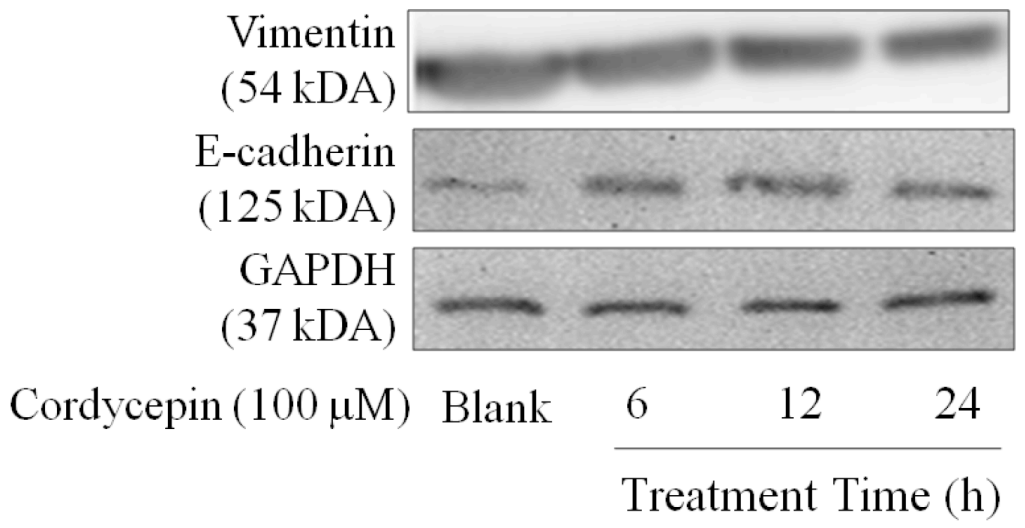

C

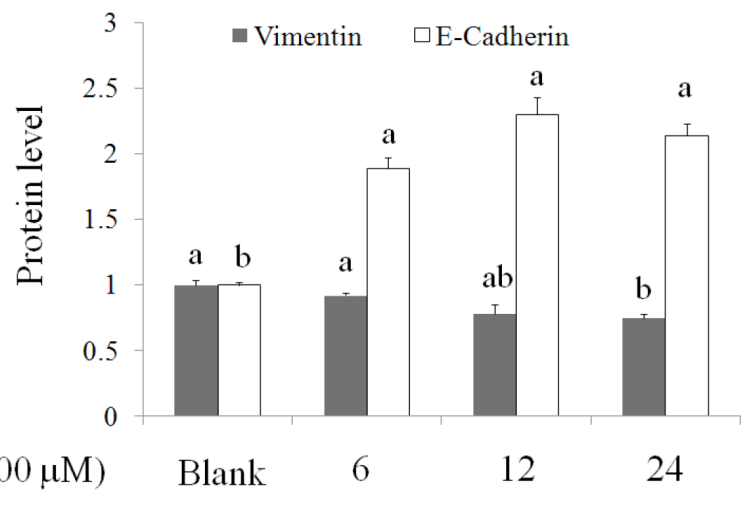

Treatment Time $(\mathrm{h})$

Figure 3: The regulations of cordycepin on EMT markers of the OVCAR-3 ovarian carcinoma cells after $24 \mathrm{~h}$ treatment, including E-cadherin (FITC) and vimentin (PE) by (A) fluorescent microscopy and (B) Western blot. Data were shown as mean $\pm \mathrm{SD}(n=3)$. ${ }^{\text {a.b }}$ values with one different letter superscript are significantly different from each other $(p<0.05)$. 
mitochondria for fusion. By contrast, dynamin-related protein-1 and fission protein (Fis)-1 separate mitochondria for fission [20, 21]. Cordycepin $(100 \mu \mathrm{M})$ significantly suppressed the mRNA levels of Mfn-1 and Mfn-2 in OVCAR-3 cells. By contrast, after $24 \mathrm{~h}$ treatment, $100 \mu \mathrm{M}$ of cordycepin elevated the mRNA level of Fis-1 (Figure 4).

\section{Effects of cordycepin on the migration in OVCAR-3 cells}

Transcription factor ERR $\alpha$ regulates mitochondrial function and cancer cell viability [22]. ERR $\alpha$ promotes mitochondrial fusion via elevating Mfn-1 and Mfn-2 proteins [21]. In addition, ERR $\alpha$ suppression results in EMT inhibition in breast cancer cells [23]. Metastasis, proliferation, and migration of A549 lung cancer cells were increased when ERR $\alpha$ overexpression [24]. We speculate that cordycepin inhibits mitochondrial activity and EMT in OVCAR-3 cells may due to ERR $\alpha$ regulation. Indeed, ERR $\alpha$ expression was decreased after cordycepin treatment at $100 \mu \mathrm{M}$ for $24 \mathrm{~h}$ (Figure 5A). We used specific small interfering (si) RNA for ERR $\alpha$ in OVCAR-3 cells to confirm our results (Figure 5B).

We subsequently investigated the migration of OVCAR-3 cells after ERR $\alpha$ knockdown and cordycepin treatment. As illustrated in Figure 6, cordycepin treatment for $24 \mathrm{~h}$ significantly suppressed the migration of OVCAR-3 cells; this result was similar to that obtained after ERR $\alpha$ knockdown. Collectively, the data revealed that cordycepin inhibited EMT and migration in OVCAR-3 cell by inducing mitochondrial fission and suppressing the mitochondrial membrane potential, and then decreasing mitochondrial activity.

\section{DISCUSSION}

Because of chemotherapy resistance and metastasis, many complementary and alternative medicine are developed in applications of cancer prevention and therapy. Traditional Chinese medicine is one of treatment for complementary and alternative therapy. Cordycepin is an active compound and has been used in cancer treatment in past clinical study.

Loss of intercellular junctions and raise of cell motility are casue by EMT in cancer cell, thereby resuting in metastasis [25]. The E-cadherin is an adhesion molecules on cell membrane, which expression is going to affect cell junction. A study has reported that reduction of E-cadherin is an target index for first stage of cancer cell metastasis [26, 27]. Subsequently, other biomarkers are also change involved in EMT, including N-cadherin, fibronectin, and vimentin $[27,28]$, leading to cancer cell migration and invasion [28-30]. We recently reported that EMT upregulation was induced by mitochondrial fusion in ovarian carcinoma cells [21].

Mitochondria undergo fission and fusion change called mitochondrial dynamics, which regulates cell metabolism, survival, and proliferation [31]. Fusion unifies the mitochondrial compartments, whereas fission generates morphologically and functionally distinct mitochondria. Mitochondrial fission often occurs early in an apoptotic event [32] and the autophagic process [33]. Mitochondrial fusion is associated with increased cell survival [34].

Our results suggest that ERR $\alpha$ elevated Mfn-1 and Mfn-2 to induce EMT, resulting in cancer cell migration. However, ERR $\alpha$ expression and EMT (E-cadherin loss

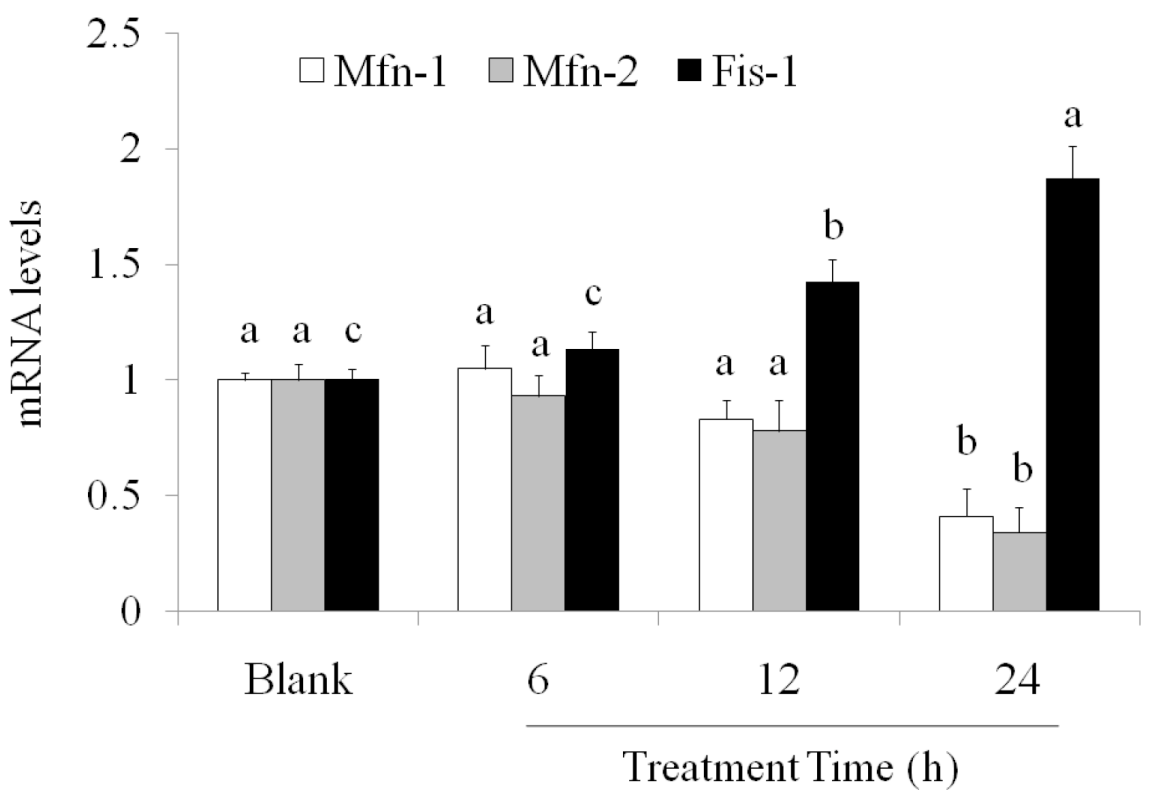

Figure 4: Effects of cordycepin on (A) Mfn1, (B) Mfn2, and (C) Fis1 mRNA levels in the OVCAR-3 ovarian carcinoma cells after $24 \mathrm{~h}$ treatment. Data were shown as mean $\pm \mathrm{SD}(n=3)$. ${ }^{\text {a.b }}$ values with one different letter superscript are significantly different from each other $(p<0.05)$. 
and vimentin elevation) in OVCAR-3 cells were inhibited by noncytotoxic concentration of cordycepin $(100 \mu \mathrm{M})$ treatment. Cordycepin suppressed mitochondrial activity, thereby avoiding EMT and ovarian carcinoma cells migration (Figure 7). This is the first study to confirm the inhibition of metastasis and migration in cordycepin-treated ovarian carcinoma cells. Moreover, our results suggested that cordycepin inhibited mitochondrial activity at noncytotoxic concentrations and suppressed ovarian carcinoma cells migration.

\section{MATERIALS AND METHODS}

\section{Chemicals}

Crystal violet, sodium dodecyl sulfate (SDS), Triton X-100, trypsin, cordycepin, and trypan blue were purchased from Sigma Chemical Co. (St. Louis, MO, USA). Fetal bovine serum (FBS) was purchased from
Life Technologies (Auckland, New Zealand). Dimethyl sulfoxide was purchased from Wako Pure Chemical Industries (Saitama, Japan). MitoTracker Deep Red-FM was purchased from Invitrogen (Carlsbad, CA, USA). Anti-vimentin and -ERR $\alpha$ antibodies were purchased from Santa Cruz (Santa Cruz, CA, USA). Anti-E-cadherin antibody was purchased from Abcam (CA, USA).

\section{Cell culture}

Human ovarian carcinoma cell lines (ES-2, SKOV3, and OVCAR-3) were grown in Dulbecco's modified Eagle medium (Gibco BRL, Grand Island, NY, USA) containing $2 \mathrm{mM}$ L-glutamine and $1.5 \mathrm{~g} / \mathrm{L}$ of sodium bicarbonate, supplemented with 10\% FBS (Gibco BRL) and 2\% penicillin-streptomycin $(10,000 \mathrm{U} / \mathrm{mL}$ of penicillin and $10 \mathrm{mg} / \mathrm{mL}$ of streptomycin). The cells were cultured in a humidified incubator at $37^{\circ} \mathrm{C}$ under $5 \% \mathrm{CO}_{2}$.

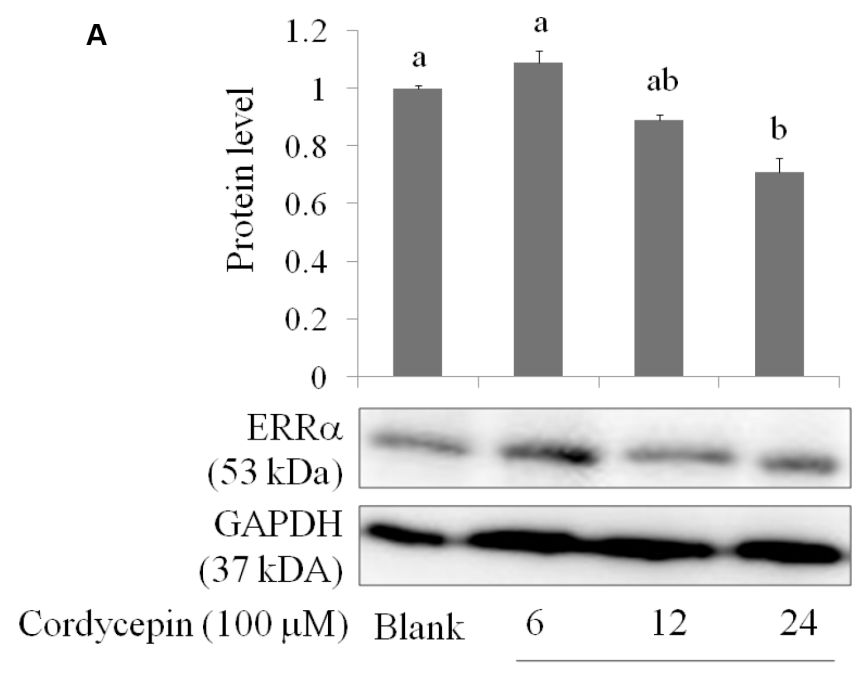

B

Treatment Time (h)

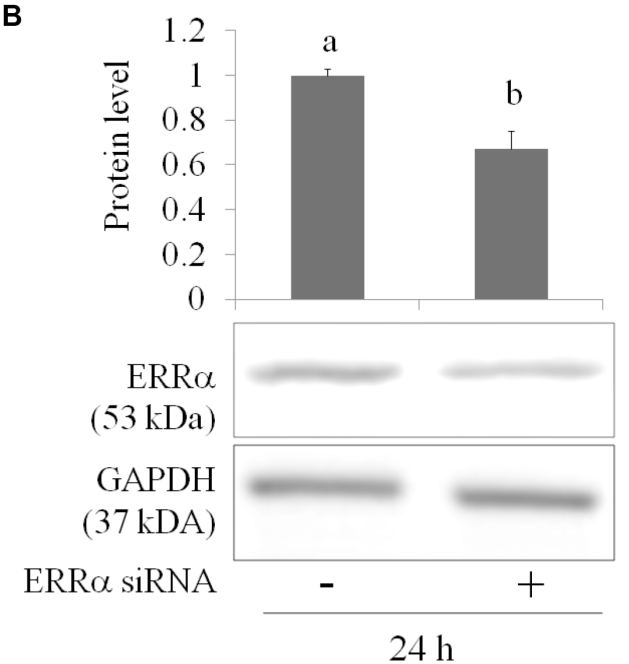

Figure 5: (A) The inhibitory effects of cordycepin on ERR $\alpha$ level of the OVCAR-3 ovarian carcinoma cells after $24 \mathrm{~h}$ treatment. (B) The attenuation of ERR $\alpha$ siRNA for $12 \mathrm{~h}$ treatment in the OVCAR-3 ovarian carcinoma cells. Data were shown as mean $\pm \mathrm{SD}(\mathrm{n}=3)$. ${ }^{\text {a.b }}$ values with one different letter superscript are significantly different from each other $(p<0.05)$. 


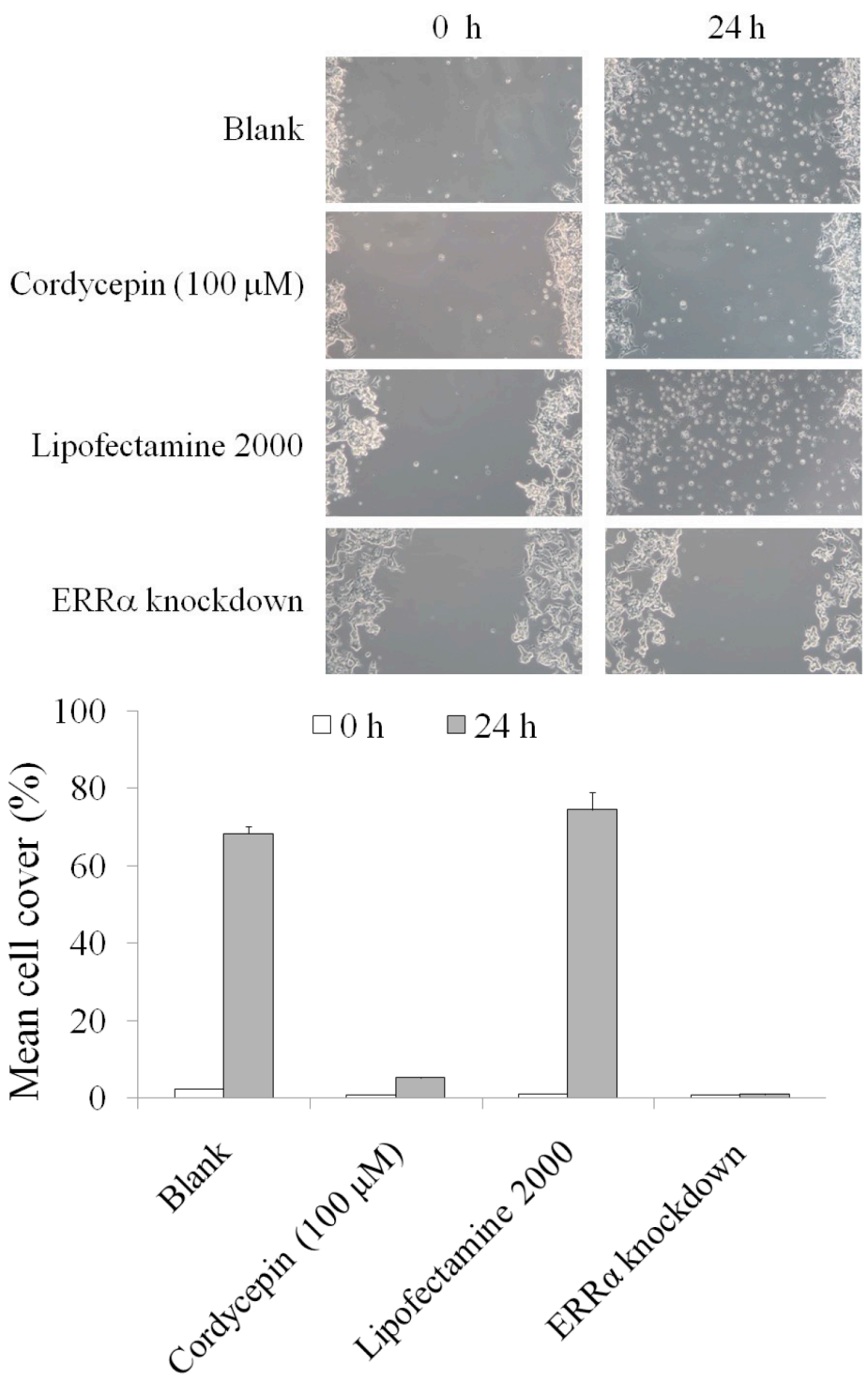

Figure 6: The inhibitory effects of migration in the OVCAR-3 human ovarian carcinoma cells treated by cordycepin for $24 \mathrm{~h}$.

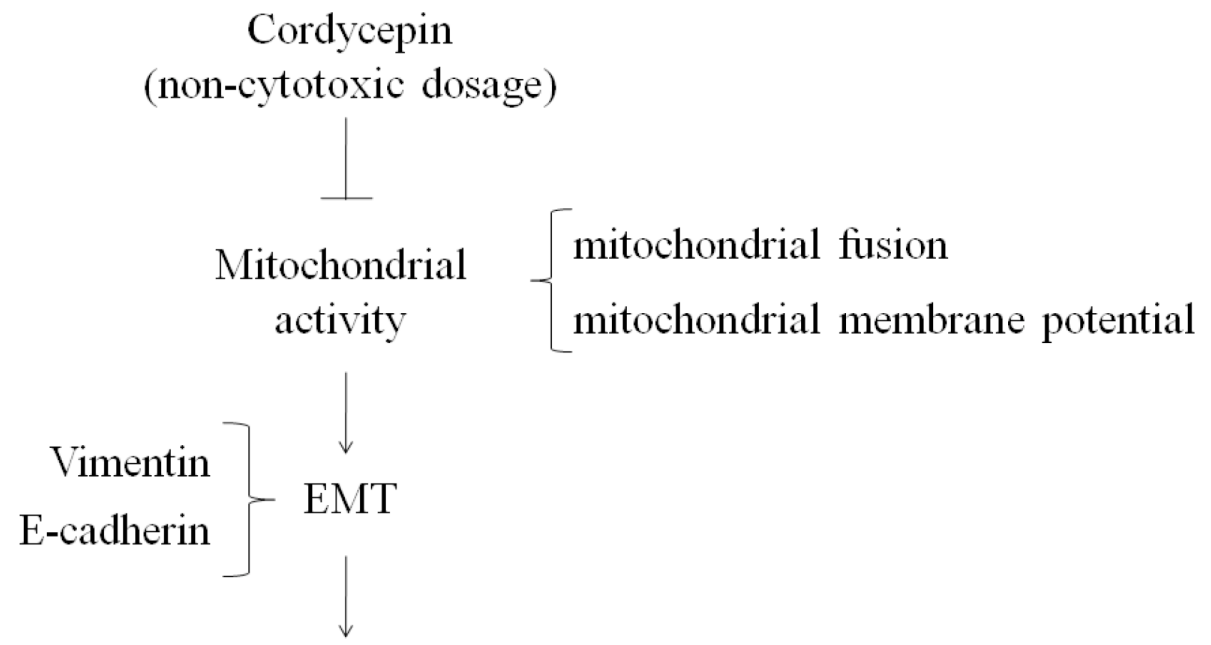

Migration/Invasion

Figure 7: The anti-invasion of cordycepin in ovarian carcinoma mediated by down-regulation of mitochondrial activity. 


\section{Cell viability}

The cytotoxic effect of cordycepin on ovarian carcinoma cells was measured using crystal violet staining assay. The cells were seeded on 24 -well plates $\left(3 \times 10^{4}\right.$ cells/well) and treated with various concentrations of cordycepin for $24 \mathrm{~h}$. The cells were subsequently washed and stained with $2 \mathrm{~g} / \mathrm{L}$ of crystal violet in phosphatebuffered formaldehyde for $20 \mathrm{~min}$. Crystal violet bound to the cells was dissolved in $20 \mathrm{~g} / \mathrm{L}$ of SDS solution, and the corresponding absorbance was measured at $600 \mathrm{~nm}$ [16].

\section{MTT assay}

The mitochondrial activity of cordycepin in ovarian carcinoma cells was measured using the MTT staining assay. The cells were seeded on 24 -well plates $\left(3 \times 10^{4}\right.$ cells/well) and treated with various concentrations of cordycepin for $24 \mathrm{~h}$. The cells were reacted with MTT $(0.5 \mathrm{mg} / \mathrm{mL})$ for $2 \mathrm{~h}$ and then washed, after which the tetrazolium was dissolved with dimethyl sulfoxide, the absorbance was measured at $570 \mathrm{~nm}$.

\section{Western blot}

Cells were rinsed and lysed using RIPA buffer with protease and phosphatase inhibitors for $20 \mathrm{~min}$ on ice. The cells were then centrifuged at $12,000 \times \mathrm{g}$ for 10 $\min$ at $4{ }^{\circ} \mathrm{C}$. Protein extracts were resolved through SDSpolyacrylamide gel electrophoresis. The protein bands were electrotransferred to nitrocellulose membranes and treated with enhanced chemiluminescence (ECL) blocking agent (GE Healthcare Bio-Sciences) in saline buffer (T-TBS) for $1 \mathrm{~h}$ and then incubated with a primary antibody overnight at $4^{\circ} \mathrm{C}$. Subsequently, the membranes were washed three times in T-TBS, and the bound antibodies were detected using appropriate horseradish peroxidase-conjugated secondary antibodies, followed by analysis in an ECL plus Western blotting detection system (GE Healthcare Bio-Sciences).

\section{Mitochondrial morphology and mitochondrial membrane potential}

Cells were treated with $250 \mathrm{nM}$ Mitotracker DeepRed FM (Invitrogen) for $30 \mathrm{~min}$ in a serum-free culture medium to determine the mitochondrial morphology. After washed the cells, the nuclei were stained with Hochest 33342 [21]. The mitochondrial morphology was observed using a confocal microscope. Mitochondrial membrane potential was measured by JC-1 staining, and the flourscent intensity was determined through microscopy.

\section{ERRa knockdown}

ERR $\alpha$ interference in OVCAR-3 cells was determined using a lipofectamine RNAiMAX transfection reagent, according to the manufacturer's protocols
(Invitrogen). The sequence of specific siRNAs for ERR $\alpha$ was purchased from Santa Cruz (Santa Cruz). Cell lysates were subjected to Western blotting with an ERR $\alpha$ antibody to confirm the inhibition of ERR $\alpha$ expression.

\section{Real-time PCR}

Total RNA was obtained using the Trizol reagent (Gibco BRL Life Technologies, Inc., Gaithersburg, MD, USA), according to the manufacturer's instructions. Primers were synthesized by MD-Bio Inc. (Taipei, Taiwan). The gene expression level was determined through relative quantitative real-time polymerase chain reaction (CFX Cycler System, Bio-Rad Laboratories, Inc., Hercules, CA, USA).

\section{Statistical analysis}

The statistical significance was determined by one-way analysis of variance (ANOVA) using the general linear model procedure of SPSS software (SPSS Institute, Inc., Chicago, IL, USA), followed by ANOVA with Duncan's test. The results were considered to be statistically significant if the $p$ value was $<0.05$.

\section{CONCLUSIONS}

Cordycepin is an active compound in various Cordyceps spp. and widely used in traditional Chinese medicine. It can considerably inhibit human ovarian carcinoma cells by suppressing EMT and mitochondrial activity through ERR $\alpha$ inhibition. Our results indicate that cordycepin has potential benefits for anti-metastasis and anti-migration in ovarian cancer therapy.

\section{CONFLICTS OF INTEREST}

None.

\section{REFERENCES}

1. Wang CW, Wang CK, Chang YJ, Choong CY, Lin CS, Tai CJ, Tai CJ. Preclinical evaluation on the tumor suppression efficiency and combination drug effects of fermented wheat germ extract in human ovarian carcinoma cells. Evid Based Compl Alt Med. 2015; 2015: Article ID570785. doi: 10.1155/2015/570785.

2. Roett MA, Evans P. Ovarian cancer: An overview. Am Fam Physician 2009; 80: 609-616.

3. Bell DA. Origins and molecular pathology of ovarian cancer. Mod Pathol. 2005; 18: S19-S32.

4. Feeley KM, Wells M. Precursor lesions of ovarian epithelial malignancy. Histopathology. 2001; 38: 87-95.

5. Thiery JP, Acloque H, Huang RY, Nieto MA. Epithelialmesenchymal transitions in development and disease. Cell. 2009; 139: 871-890. 
6. Lai YJ, Tai CJ, Wang CW, Choong CY, Lee BH, Shi YC, Tai CJ. Anti-cancer activity of Solanum nigrum (AESN) through suppression of mitochondrial function and epithelialmesenchymal transition (EMT) in breast cancer cells. Molecules. 2016; 21. doi: 10.3390/molecules21050553.

7. Aktas B, Tewes M, Fehm T, Hauch S, Kimmig R, KasimirBauer S. Stem cell and epithelial-mesenchymal transition markers are frequently overexpressed in circulating tumor cells of metastatic breast cancer patients. Breast Cancer Res. 2009; 11: R46. doi: 10.1186/bcr2333.

8. Yu M, Bardia A, Wittner BS, Stott SL, Smas ME, Ting DT, Isakoff SJ, Ciciliano JC, Wells MN, Shah AM. Circulating breast tumor cells exhibit dynamic changes in epithelial and mesenchymal composition. Science. 2013; 339: 580-584.

9. Mani SA, Guo W, Liao MJ, Eaton EN, Ayyanan A, Zhou AY, Brooks M,; Reinhard F, Zhang CC, Shipitsin M. The epithelial-mesenchymal transition generates cells with properties of stem cells. Cell. 2008; 133: 704-715.

10. Nakamura K, Shinozuka K, Yoshikawa N. Anticancer and antimetastatic effects of cordycepin, an active component of Cordyceps sinensis. J Pharmacol Sci. 2015; 127: 53-56.

11. Yoshikawa N, Nakamura K, Yamaguchi Y, Kagota S, Shinozuka K, Kunitomo M. Antitumour activity of cordycepin in mice. Clin Exp Pharmacol Physiol. 2004; 31: S51-S53.

12. Wehbe-Janek H, Shi Q, Kearney CM. Cordycepin/ hydroxyurea synergy allows low dosage efficacy of cordycepin in MOLT-4 leukemia cells. AntiCancer Res. 2007; 27: 3143-3146.

13. Nakamura K, Konoha K, Yoshikawa N, Yamaguchi Y, Kagota S, Shinozuka K, Kunitomo M. Effect of cordycepin (3'-deoxyadenosine) on hematogenic lung metastatic model mice. In Vivo. 2005; 19: 137-142.

14. Wang XA, Xiang SS, Li HF, Wu XS, Li ML, Shu YJ, Zhang F, Cao Y, Ye YY, Bao RF. Cordycepin induces S phase arrest and apoptosis in human gallbladder cancer cells. Molecules. 2014; 19: 11350-11365.

15. Wang CW, Tai CJ, Choong CY, Lin YC, Lee BH, Shi YC, Tai CJ. Aqueous extract of Paris polyphylla (AEPP) inhibits ovarian cancer via suppression of peroxisome proliferatoractivated receptor-gamma coactivator (PGC)-1alpha. Molecules. 2016; 21: doi: 10.3390/molecules21060727.

16. Hsu WH, Lee BH, Pan TM. Red mold diocorea-induced G2/M arrest and apoptosis in human oral cancer cells. J Sci Food Agric 2010; 90: 2709-2715.

17. Chang J, Wang H, Wang X, Zhao Y, Zhao D, Wang C, Li Y, Yang Z, Lu S, Zeng Q. Molecular mechanisms of polyphllin I-induced apoptosis and reversal of the epithelialmesenchymal transition in human osteosarcoma cells. J Ethnopharmacol. 2015; 170: 117-127.

18. Cooke VG, LeBleu VS, Keskin D, Khan Z, O'Connell JT, Teng Y, Duncan MB, Xie L, Maeda G, Vong S. Pericyte depletion results in hypoxia-associated epithelial-tomesenchymal transition and metastasis mediated by met signaling pathway. Cancer Cell. 2012; 21: 66-81.
19. Nauseef JT, Henry MD. Epithelial-to-mesenchymal transition in prostate cancer: paradigm or puzzle? Nat Rev Urol. 2011; 8: 428-439.

20. Verdejo HE, Del Campo A, Troncoso R, Gutierrez T, Toro B, Quiroga C. Mitochondria, myocardial remodeling, and cardiovascular disease. Curr Hypertens Rep. 2012; 14: 532-539.

21. Hsu WH, Lee BH, Pan TM. Leptin-indcued mitochondrial fusion mediates hepatic lipid accumulation. Int J Obesity. 2015; 39: 1750-1756.

22. Chang CY, McDonnell DP. Molecular pathways: The metabolic regulator estrogen-related receptor alpha as a therapeutic target in cancer. Clin Cancer Res. 2012; 18: 6089-6095.

23. Wu YM, Chen ZJ, Liu H, Wei WD, Lu LL, Yang XL, Liang WT, Liu T, Liu HL, Du J. Inhibition of ERRa suppresses epithelial mesencymal transition of triple negative breast cancer cells by directly targeting fibronectin. Oncotarget. 2015; 6: 25588-25601. doi: 10.18632/ oncotarget.4436.

24. Huang JW, Guzn BZ, Yin LH, Liu FN, Hu B, Zheng QY, Li FL, Zhong YX, Chen Y. Effects of estrogen-related receptor alpha $(E R R \alpha)$ on proliferation and metastasis of human lung cancer A549 cells. J Huazhong Univ Sci Technol Med Sci. 2014; 34: 875-881.

25. Thiery JP, Sleeman JP. Complex networks orchestrate epithelial-mesenchymal transitions. Nat Rev Mol Cell Biol. 2006; 7: 131-142.

26. Murakami A, Nakagawa T, Fukushima C, Torii M, Sueoka K, Nawata S, Takeda O, Ishikawa H, Sugino N. Relationship between decreased expression of squamous cell carcinoma antigen 2 and E-cadherin in primary cervical cancer lesion and lymph node metastasis. Oncol Rep. 2008; 19: 99-104.

27. Thiery JP. Epithelial-mesenchymal transitions in tumour progression. Nat Rev Cancer. 2002; 2: 442-454.

28. Mulholland DJ, Kobayashi N, Ruscetti M, Zhi A, Tran LM, Huang J, Gleave M, Wu H. Pten loss and RAS/MAPK activation cooperate to promote EMT and metastasis initiated from prostate cancer stem/progenitor cells. Cancer Res. 2012; 72: 1878-1889.

29. Byles V, Zhu L, Lovaas JD, Chmilewski LK, Wang J, Faller DV, Dai Y. SIRT1 induces EMT by cooperating with EMT transcription factors and enhances prostate cancer cell migration and metastasis. Oncogene. 2012; 31: 4619-4629.

30. Darai E, Scoazec JY, Walker-Combrouze F, MlikaCabanne N, Feldmann G, Madelenat P, Potet F. Expression of cadherins in benign, borderline, and malignant ovarian epithelial tumors: a clinicopathologic study of 60 cases. Hum Pathol. 1997; 28: 922-928.

31. Westermann B. Mitochondrial fusion and fission in cell life and death. Nat Rev Mol Cell Biol. 2010; 11: 872-884.

32. Lee YJ, Jeong SY, Karbowski M, Smith CL, Youle RJ. Roles of the mammalian mitochondrial fission and fusion mediators Fis1, Drp1, and Opa1 in apoptosis. Mol Biol Cell. 2004; 15: 5001-5011. 
33. Twig G, Elorza A, Molina AJ, Mohamed H, Wikstrom JD, Walzer G, Stiles L, Haigh SE, Katz S, Las G, Alroy J, Wu M, Py BF, Yuan J, Deeney JT, Corkey BE. Fission and selective fusion govern mitochondrial segregation and elimination by autophagy. EMBO J. 2008; 27: 433-446.
34. Gomes LC, Scorrano L. Mitochondrial elongation during autophagy: a stereotypical response to survive in difficult times. Autophagy 2011; 7: 1251-1253. 